\title{
Imitative Response Tendencies in Patients With Frontal Brain Lesions
}

\author{
Marcel Brass and Jan Derrfuss \\ Max Planck Institute of Cognitive Neuroscience \\ Gabriele Matthes-von Cramon \\ University of Leipzig \\ D. Yves von Cramon \\ Max Planck Institute of Cognitive Neuroscience and University of Leipzig
}

\begin{abstract}
It is widely accepted that patients with frontal lesions have problems inhibiting automatic response tendencies. Whereas inhibition deficits of overlearned responses have been extensively investigated using interference tasks like the Stroop task (J. R. Stroop, 1935), it is controversial whether patients with frontal brain lesions also have problems inhibiting imitative responses. Using an interference paradigm, the present study investigated imitative response tendencies in patients with frontal lesions. In addition, it tested whether patients deficient in the inhibition of imitative responses correspondingly have problems inhibiting overlearned responses. It was found that the group with frontal lesions displayed significantly stronger imitative response tendencies than the group with nonfrontal lesions. Furthermore, it was shown that the inhibition of imitative responses is functionally unrelated to Stroop interference.
\end{abstract}

Although imitation plays a major role in the acquisition of motor skills and language, the functional and neuronal mechanisms underlying imitation have hardly been investigated. Only recently have neurocognitive findings opened up a new perspective for the understanding of imitation (Rizzolatti, Fogassi, \& Gallese, 2001). Research with nonhuman primates has demonstrated that so-called mirror neurons in the premotor cortex of monkeys code observed and executed actions (Di Pellegrino, Fadiga, Fogassi, Gallese, \& Rizzolatti, 1992; Gallese, Fadiga, Fogassi, \& Rizzolatti, 1996), indicating the tight relationship of action observation and action execution. In addition, neuroimaging studies suggest that action observation leads to an activation of cortical structures that were previously thought to be related to action planning and execution (Decety et al., 1997; Grezes, Costes, \& Decety, 1999; Iacoboni et al., 1999; Nishitani \& Hari, 2000). It was further found that the ventrolateral premotor cortex is involved in imitative behavior, which suggests that imitation is achieved by a direct mapping of the observed action onto a motor representation (Iacoboni et al., 1999). If this assumption holds true, one might expect an automatic tendency to imitate.

\section{Imitative Response Tendencies in Patients With Frontal Lesions}

These findings cast some new light on neuropsychological findings suggesting that patients with frontal lesions

Marcel Brass and Jan Derrfuss, Max Planck Institute of Cognitive Neuroscience, Leipzig, Germany; Gabriele Matthes-von Cramon, Day Care Clinic of Cognitive Neurology, University of Leipzig, Leipzig, Germany; D. Yves von Cramon, Max Planck Institute of Cognitive Neuroscience, and Day Care Clinic of Cognitive Neurology, University of Leipzig.

Correspondence concerning this article should be addressed to Marcel Brass, Max Planck Institute of Cognitive Neuroscience, Stephanstrasse 1A, Leipzig D-04103, Germany. E-mail: brass@cns .mpg.de sometimes display unintended imitative response tendencies. These tendencies were called echopractic responses by Luria (1966). He suggested that they were found only in patients with frontal lesions. He investigated such tendencies using a task in which patients were instructed to execute an action that was incongruent with the action executed by the examiner (extending the index finger when the examiner shows a fist and vice versa). Despite this early evidence for deficits in the inhibition of imitative response tendencies in patients with frontal lesions, little research has been carried out following Luria's observations.

A few decades later, Lhermitte, Pillon, and Serdaru (1986) described a syndrome that was called imitation behavior. Patients displaying imitation behavior were not able to inhibit imitative responses, even when they were explicitly told to stop imitation. Lhermitte and colleagues concluded that imitation behavior is frequent in patients with frontal lobe lesions and that it is caused by lesions to the mediobasal cortex. The only attempt to replicate these findings was carried out by De Renzi and colleagues (De Renzi, Cavalleri, \& Facchini, 1996). They found the incidence rate of imitation behavior to be much lower than that reported by Lhermitte and colleagues. Furthermore, they suggested that imitation behavior is related to medial and lateral lesions. Nevertheless, both of these studies suggest that imitative response tendencies are very specific for patients with frontal lobe lesions. For this reason, identifying such tendencies might be very useful for diagnostic purposes. The method introduced by Lhermitte and colleagues, however, has the shortcoming that it is only suited to identifying patients who show overt imitative responses. There might be a way to uncover cases with latent imitative response tendencies by using an interference paradigm as suggested by Luria (1966).

In behavioral studies such a paradigm was devised to investigate imitative response tendencies in healthy participants. This paradigm is kind of a Simon task (Simon \& Rudell, 1967) in which participants are required to respond 
to a symbolic stimulus with an instructed finger movement while observing interfering finger movements that are not response relevant (Brass, Bekkering, Wohlschläger, \& Prinz, 2000). In the present study we applied this paradigm to patients with frontal and nonfrontal brain lesions and control participants in order to clarify whether patients with frontal lesions display latent imitative response tendencies. In addition, we wanted to investigate whether patients showing problems in inhibiting imitative response tendencies also have problems in inhibiting overlearned response tendencies as was tested in the Stroop task (Stroop, 1935).

\section{Method}

\section{Participants}

We tested a group of patients with frontal lesions $(n=16$, mean age $=47.7$ years), a group of patients with nonfrontal (posterior) lesions ( $n=14$, mean age $=45.0$ years), and a control group ( $n=16$, mean age $=47.1$ years). The two patient groups were chosen from a database of the Day Care Clinic of Cognitive Neurology in Leipzig. They were assigned to the groups by an experienced neurologist (D. Yves von Cramon) according to their magnetic resonance imaging (MRI) scans. Because of clipping of the anterior communicating artery, for 2 patients an MRI scan could not be performed. They were assigned on the basis of computerized tomography scans performed in the acute care clinic. Because we intended to include a heterogeneous sample in the study, the only selection criteria were the lesion site and the ability to understand the instructions of the different neuropsychological tests.

Two of the 30 patients were still under treatment at the clinic and were approached personally by their therapists. The other patients were contacted by mail and telephone. All patients gave informed consent to participate in the study. The control group was chosen on the basis of age, education, and gender to match the patient group with frontal lesions. Details concerning the groups are given in Table 1. The three groups did not differ with respect to age and education. The amount of time that had passed since the date of injury differed slightly for the two patient groups, although this difference was not significant, $t(27)=0.28, p=.77$. The patient groups did not differ with respect to their premorbid intelligence as assessed by the Multiple Word-Choice Test (MWT; see below; Lehrl, 1999).

One participant from the control group was excluded from the study because her test score on the imitation-inhibition task was more than 7 standard deviations above the mean of the control group. Three patients were not able to perform all tasks. However, we decided to include these patients in the study but exclude the results from the missing tests in the data sets of their matched controls.

\section{Procedure}

Imitation-inhibition task. The imitation-inhibition task was presented on a $17-i n .(43.18 \mathrm{~cm})$ color monitor that was controlled by a DOS-compatible computer running the experimental software Experimental Run Time System, Version 3.28 (Beringer, 1995). Reaction times were recorded with a custom-built response device, which was equipped with four touch sensitive buttons.

Participants were instructed to place their right hand on the response device with the index finger on one button and the middle finger on the other. Thus, there were two possible response alternatives. Thereafter, they were presented with video sequences of a hand. The video sequences started with a frame showing the hand in a resting position (see Figure 1). This initial frame was the same for all conditions. After this initial frame the number 1 or 2 appeared between the index and the middle finger of the videotaped hand. Participants were asked to lift their index finger when 1 was presented and to lift their middle finger when 2 was presented. The task consisted of three different conditions. In the baseline condition only the number was presented while the hand on the screen remained motionless. In the congruent condition the corresponding finger on the screen was lifted simultaneously with presentation of the digit (e.g., the index finger was lifted when 1 was presented). In the incongruent condition the noncorresponding finger was lifted (e.g., the middle finger was lifted when $l$ was presented). The detailed timing of the experimental trial was as follows. The initial frame showing the hand was presented for 2,000 ms. Then the number was presented simultaneously with the first frame $(34 \mathrm{~ms})$, which showed a finger movement. This frame was followed by a second movement frame ( $34 \mathrm{~ms}$ ), and the video sequence ended with the finger in the lifted end position $(1,240 \mathrm{~ms})$. The intertrial interval was $2 \mathrm{~s}$.

The imitation-inhibition task started with a 20 -trial practice phase. Participants were instructed to give a quick and possibly correct response. The experimental part consisted of three 50-trial blocks with short breaks between them. The three types of trials (baseline, congruent, and incongruent) were presented randomly.

Computerized manual Stroop task. We decided to use computerized and manual versions of the Stroop task in order to investigate the inhibition of overlearned response tendencies. First of all, we wanted to assess reaction times in addition to errors. Second, we wanted the Stroop task to be as similar as possible to the imitation-inhibition task. The same computer equipment and programs were used as in the imitation-inhibition task. Participants were instructed to place the middle and the index finger of

Table 1

Main Clinical Data

\begin{tabular}{|c|c|c|c|c|c|c|c|c|c|c|c|}
\hline \multirow[b]{2}{*}{ Group } & \multicolumn{2}{|c|}{ Age } & \multirow{2}{*}{$\begin{array}{l}\text { Gender } \\
(\mathrm{M} / \mathrm{F})\end{array}$} & \multicolumn{2}{|c|}{$\begin{array}{c}\text { Education } \\
\text { (years) }\end{array}$} & \multicolumn{2}{|c|}{$\begin{array}{c}\text { TSI } \\
\text { (months) }\end{array}$} & \multirow{2}{*}{$\begin{array}{l}\text { Etiology } \\
\text { (T/V/N/I) }\end{array}$} & \multirow{2}{*}{$\begin{array}{c}\text { Side } \\
(\mathrm{L} / \mathrm{R} / \mathrm{Bi})\end{array}$} & \multicolumn{2}{|c|}{ MWT score } \\
\hline & $M$ & $S D$ & & $M$ & $\overline{S D}$ & $M$ & $\overline{S D}$ & & & $M$ & $S D$ \\
\hline $\begin{array}{l}\text { Frontal lesion } \\
\quad(n=16) \\
\text { Nonfrontal lesion }\end{array}$ & 47.7 & 12.2 & $11 / 5$ & 10.3 & 1.1 & 66 & 82 & $4 / 10 / 2 / 0$ & $7 / 4 / 6$ & 28.7 & 3.0 \\
\hline $\begin{array}{l}(n=14) \\
\text { Control }(n=16)\end{array}$ & $\begin{array}{l}45.0 \\
47.1\end{array}$ & $\begin{array}{l}11.3 \\
12.5\end{array}$ & $\begin{array}{l}10 / 4 \\
11 / 5\end{array}$ & $\begin{array}{l}10.4 \\
10.3\end{array}$ & $\begin{array}{l}1.9 \\
1.2\end{array}$ & 54 & 64 & $5 / 7 / 1 / 1$ & $7 / 5 / 2$ & $\begin{array}{l}28.5 \\
31.1\end{array}$ & $\begin{array}{l}4.6 \\
3.0\end{array}$ \\
\hline
\end{tabular}

Note. $\mathrm{M}=$ male; $\mathrm{F}=$ female; $\mathrm{TSI}=$ time since injury; $\mathrm{T}=$ traumatic; $\mathrm{V}=$ vascular; $\mathrm{N}=$ neoplastic; $\mathrm{I}=$ infectious; $\mathrm{L}=$ left; $\mathrm{R}=$ right; $\mathrm{Bi}=$ bilateral; MWT $=$ Multiple Word-Choice Test. 


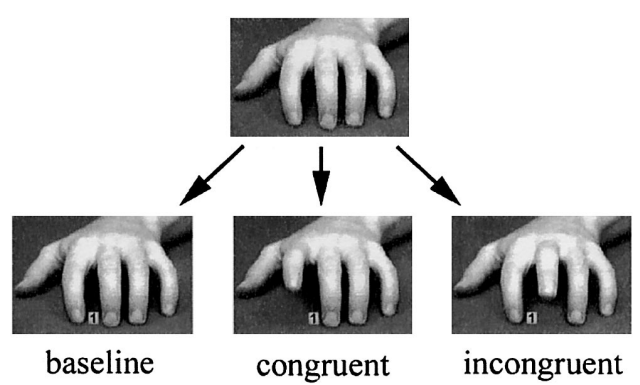

Figure 1. Baseline, congruent, and incongruent trials in the imitation-inhibition task. In baseline trials, only a number was presented between the index and middle finger to indicate which finger movement had to be executed. In congruent trials, the observed finger movement was congruent to the instructed finger movement. In incongruent trials, the instructed finger movement and the observed finger movement were different.

their left and right hands on the response buttons. Thus, there were four possible response alternatives. Stimuli in the colors red, green, blue, or yellow were presented in the middle of the computer screen (see Figure 2). Below the stimuli, a two-letter abbreviation of the German color words rot (red), blau (blue), gelb (yellow), or grün (green) was shown. To minimize the working memory load, we presented these letters on each trial. In the baseline condition $X X X X$ was presented on the screen colored in one of the four possible colors. In the congruent condition color words were presented in their matching color (e.g., RED in red). In the incongruent condition color words were presented in the nonmatching color (e.g., RED in blue). Participants had to respond by lifting the finger that matched the color of the presented item. Each trial started with the presentation of a fixation cross. After $100 \mathrm{~ms}$ of a blank screen, the item and the abbreviations of the colors were presented until the participant responded. The Stroop task started with a 20-trial practice phase. Afterward two blocks of 60 experimental trials followed.

Other frontal tests. In addition to the two computerized inhibition tasks, we administered a number of other tests that are commonly used to diagnose frontal brain damage. One of the most commonly used frontal tests is the Wisconsin Card Sorting Test (WCST; Grant \& Berg, 1948), which we administered in the modified version. The Modified Wisconsin Card Sorting Test (MCST) was developed by Nelson (1976). This test requires the sorting of a pile of cards according to changing sorting criteria. Three error types are computed: Perseveration errors occur when participants continue to sort according to a previously relevant sorting criterion. Conceptual losses are defined as errors after three or more consecutive correct answers. Total errors are computed by adding together perseverative errors, conceptual losses, and random errors. Furthermore, the number of correctly achieved categories is computed. Another so-called frontal lobe task is the Verbal Fluency task (Performance Assessment System, or LPS; Horn, 1983). For this task the participant has to write down as many words as possible beginning with the letters $F, K$, and $R$. For each letter the participant is given $1 \mathrm{~min}$ of time. To test verbal working memory, we used a German adaptation of the Digit Ordering Test (DOT) developed by Hoppe, Müller, Werheid, Thöne, and von Cramon (2000). In this test, participants are required to reorder a sequence of numerals in ascending order. This working memory test was found to be sensitive to frontal lobe damage (Werheid et al., 2002).

Premorbid intelligence. We applied the MWT to assess premorbid intellectual functioning (Lehrl, 1999). On this test participants have to identify words in a series of words and nonwords. The score is the number of correctly identified words. This test is functionally equivalent to the National Adult Reading Test (Nelson \& Willison, 1991).

General procedure. Each session started either with the manual Stroop task or the imitation-inhibition task. The order was counterbalanced across participants. The order of the other tasks was fixed: Verbal Fluency, MCST, MWT, and DOT.

\section{Results}

\section{Group Differences for the Imitation-Inhibition Task and the Stroop Task}

Our major aim was to test whether patients with frontal lesions have problems in inhibiting imitative response tendencies. In addition, we wanted to investigate how these patients perform in the manual Stroop task. In order to do so, we computed the difference between incongruent and congruent errors (in percentages) in the imitation-inhibition task as an indicator of response inhibition. In the Stroop task, we computed the same interference score (incongruent - congruent). A one-way analysis of variance (ANOVA) of the imitation-inhibition interference score

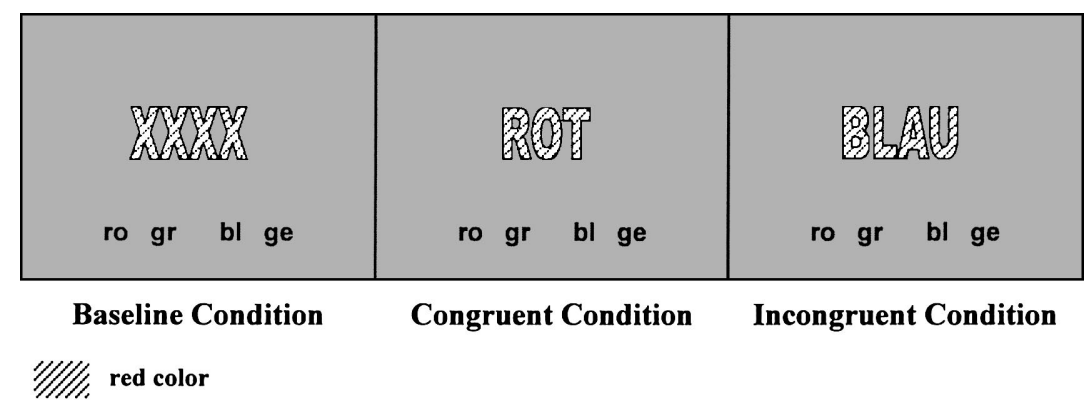

Figure 2. Schematic drawing of the manual Stroop task. In this task, participants were instructed to press one of four keys that corresponded to the color in which an item was presented. In baseline trials, $X X X X$ was presented in one of four colors. In congruent trials, the color word was presented in the corresponding color. In incongruent trials, the color word and the color of the word were different. ROT is the German word for red; BLAU is the German word for blue; ro, gr, bl, and ge are, respectively, the first two letters of the German words rot, grün (green), blau, and gelb (yellow). 
showed a main effect for experimental group, $F(2$, $43)=4.10, p<.05$. Paired comparisons indicated that the group with frontal lesions had a higher interference score than the group with posterior lesions, $t(28)=2.43, p<.05$, and the control group, $t(30)=2.05, p<.05$, whereas the group with posterior lesions did not differ significantly from the control group, $t(28)=-0.55, p=.58$ (see Figure 3). These results were also supported by nonparametric tests. An inspection of individual participants' data revealed that predominantly patients with lateral frontal lesions were impaired in the imitation-inhibition task (see Table 2).

For the Stroop task the ANOVA was only marginally significant, $F(2,40)=2.89, p=.07$. Planned comparisons showed that the difference between the group with frontal lesions and the control group was statistically significant, $t(28)=2.19, p<.05$, whereas the difference between the group with frontal lesions and the group with posterior lesions was not significant, $t(26)=0.91, p=.37$ (see Figure 4). Furthermore, the difference between the group with posterior lesions and the control group was significant, $t(26)=2.24, p<.05$. As a remarkable side effect, the reaction time difference between incongruent and congruent trials for both the imitation-inhibition task, $F(2,43)=0.58$, $p=.56$, and the Stroop task showed no significant differences between the three groups, $F(2,40)=1.07, p=.33$.

\section{Relation Between the Imitation-Inhibition Task and the Stroop Task}

A second issue we wanted to investigate in the present study was whether deficient inhibition of prepotent response tendencies in the Stroop task was related to deficient inhibition in the imitation-inhibition task. The correlation of the two interference scores in the patient group with frontal lesions showed that these two tasks were widely unrelated, $r=-.04, p=.88$. This result was also supported by an inspection of the data of individual participants. The 5 patients who showed the highest interference score in the imitation-inhibition task were not strongly impaired in the Stroop task and vice versa (see Table 2). A third indication for this assumption is the correlational pattern of both tasks with other frontal lobe tasks (see Table 3). Whereas the

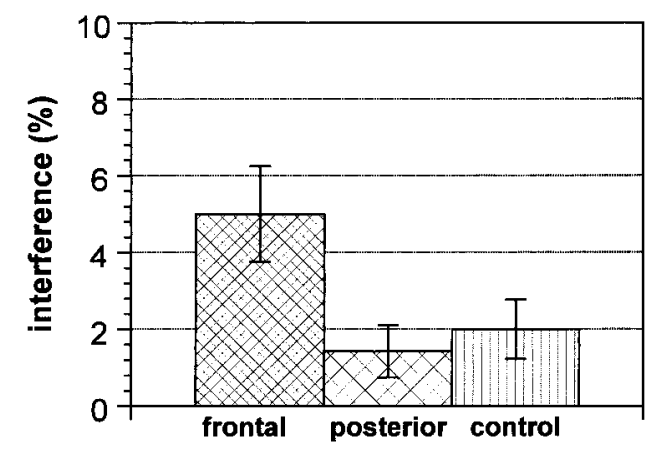

Figure 3. Mean group differences in the imitation-inhibition task. Interference scores indicate the percentage of error difference between the incongruent and the congruent conditions. Vertical bars represent standard errors of the mean.
Stroop task was positively correlated with perseveration errors on the MCST, there was no significant correlation of perseveration errors with the imitation-inhibition task. This difference in correlation coefficients turned out to be significant $(p<.05)$.

\section{Performance in Other Frontal Lobe Tasks}

Finally, we wanted to assess the performance in other frontal lobe tasks, to evaluate the strength of the frontal symptoms of the patient group with frontal lesions. A onefactorial ANOVA for perseveration errors on the MCST yielded no significant effect, $F(2,40)=1.07, p=.35$. Post hoc $t$ tests demonstrated that there were no significant differences between the three groups. The same applies for categories, $F(2,40)=0.99, p=.37$; the conceptual losses, $F(2,40)=1.03, p=.36$; and the total error score, $F(2$, $40)=1.30, p=.28$ (see Table 4$)$. The verbal fluency test showed a significant main effect for group, $F(2,40)=5.69$, $p<.01$. Post hoc comparisons revealed a significant difference for both patient groups and the control group but no difference between the patient groups, $t(26)=0.93, p=$ .36. The DOT showed no significant difference between the three groups, $F(2,41)=1.68, p=.19$.

\section{Discussion}

The present study demonstrates that patients with frontal lesions and relatively mild impairments in a number of frontal tasks have problems in inhibiting imitative response tendencies. This finding has important implications for the understanding of the cortical mechanisms underlying imitation as well as for the understanding of automatic imitative response tendencies in patients with frontal lesions. Furthermore, our results corroborate earlier findings demonstrating that patients with frontal lesions-especially in the chronic state of their disease-may not have significant deficits in classic frontal lobe tasks, for example, in the WCST (Anderson, Damasio, Jones, \& Tranel, 1991; Grafman, Jonas, \& Salazar, 1990; Mountain \& Snow, 1993).

\section{The Prepotency of Imitative Actions}

Whereas it is plausible to assume that overlearned responses evoke automatic response tendencies, this assumption is less reasonable for imitative responses. For overlearned responses, such as reading, the prepotency of the response is simply based on the learned relationship of stimulus and response (S-R). But why should a tendency to execute imitative responses exist? This tendency cannot be caused by learned S-R associations, because imitation is not a very frequent response to an observed action. Recent neurocognitive findings suggest that the prepotency of imitative actions is based on a structural mechanism that directly maps the observed action onto the equivalent motor representation (Brass, Bekkering, \& Prinz, 2001; Iacoboni et al., 1999; Rizzolatti et al., 2001). Every time an action is observed, an automatic tendency to execute that action is evoked. Usually, these automatic response tendencies are inhibited. However, under specific circumstances this inhi- 
Table 2

Interference Scores for the Imitation-Inhibition Task and the Stroop Task, as Well as Lesion Site for the Patient Groups

\begin{tabular}{|c|c|c|c|c|}
\hline $\begin{array}{l}\text { Patient } \\
\text { no. }\end{array}$ & $\begin{array}{r}\text { Imitation-inhibition } \\
\quad(\% \text { interference })\end{array}$ & $\begin{array}{c}\text { Stroop } \\
\text { (\% interference) }\end{array}$ & Side & Lesion site \\
\hline \multicolumn{5}{|c|}{ Patient group with frontal lesions } \\
\hline $\begin{array}{r}210 \\
245 \\
300 \\
403 \\
4 \\
38 \\
64 \\
237 \\
495 \\
165 \\
225 \\
415 \\
347 \\
439 \\
102 \\
150\end{array}$ & $\begin{array}{r}0 \\
0 \\
0 \\
0 \\
2 \\
2 \\
2 \\
2 \\
4 \\
6 \\
6 \\
\mathbf{8} \\
\mathbf{1 0} \\
\mathbf{1 0} \\
\mathbf{1 2} \\
\mathbf{1 6}\end{array}$ & $\begin{array}{r}-2 \\
2 \\
-5 \\
\mathbf{1 7} \\
-2 \\
0 \\
7 \\
\mathbf{5 7} \\
\mathbf{2 0} \\
10 \\
\mathbf{3 5} \\
\mathbf{1 7} \\
10 \\
0 \\
2 \\
0\end{array}$ & $\begin{array}{l}\mathrm{Bi} \\
\mathrm{Bi} \\
\mathrm{Bi} \\
\mathrm{L} \\
\mathrm{R} \\
\mathrm{Bi} \\
\mathrm{L} \\
\mathrm{L} \\
\mathrm{R} \\
\mathrm{Bi} \\
\mathrm{L} \\
\mathrm{R} \\
\mathrm{R} \\
\mathrm{L} \\
\mathrm{L} \\
\mathrm{Bi}\end{array}$ & $\begin{array}{l}\text { Polar } \\
\text { Orbital } \\
\text { Orbital, CC } \\
\text { Lateral } \\
\text { Polar } \\
\text { Orbital } \\
\text { Lateral } \\
\text { Lateral } \\
\text { Lateral } \\
\text { Polar, orbital, lateral } \\
\text { Polar, orbital } \\
\text { Lateral } \\
\text { Lateral } \\
\text { Lateral } \\
\text { Lateral } \\
\text { Polar, orbital }\end{array}$ \\
\hline \multicolumn{5}{|c|}{ Patient group with nonfrontal lesions } \\
\hline $\begin{array}{r}28 \\
328 \\
317 \\
351 \\
371 \\
372 \\
542 \\
93 \\
307 \\
318 \\
362 \\
337 \\
252 \\
315\end{array}$ & $\begin{array}{r}-2 \\
-2 \\
0 \\
0 \\
0 \\
0 \\
0 \\
2 \\
2 \\
2 \\
2 \\
4 \\
6 \\
6\end{array}$ & $\begin{array}{r}20 \\
5 \\
0 \\
-5 \\
0 \\
7 \\
5 \\
0 \\
10 \\
2 \\
22 \\
10 \\
10 \\
0\end{array}$ & $\begin{array}{l}\mathrm{L} \\
\mathrm{R} \\
\mathrm{L} \\
\mathrm{Bi} \\
\mathrm{L} \\
\mathrm{L} \\
\mathrm{L} \\
\mathrm{R} \\
\mathrm{L} \\
\mathrm{R} \\
\mathrm{Bi} \\
\mathrm{R} \\
\mathrm{L} \\
\mathrm{L}\end{array}$ & $\begin{array}{l}\text { Temporal, occipital } \\
\text { Temporal, parietal } \\
\text { Temporal } \\
\text { Temporal } \\
\text { Temporal, parietal } \\
\text { Temporal, parietal } \\
\text { Temporal, occipital } \\
\text { Temporal, occipital } \\
\text { Temporal } \\
\text { Parietal, occipital } \\
\text { Temporal, parietal } \\
\text { Temporal, parietal } \\
\text { Temporal } \\
\text { Temporal }\end{array}$ \\
\hline
\end{tabular}

Note. The values in boldface are the scores of the 5 patients showing the greatest frontal impairment in both tasks. $\mathrm{Bi}=$ bilateral; $\mathrm{CC}=$ corpus callosum; $\mathrm{L}=$ left; $\mathrm{R}=$ right.

bition mechanism fails. Similar imitative response tendencies were experimentally demonstrated in brain-healthy participants only recently. Fadiga, Fogassi, Pavesi, and Rizzolatti (1995), for instance, showed that the mere observation

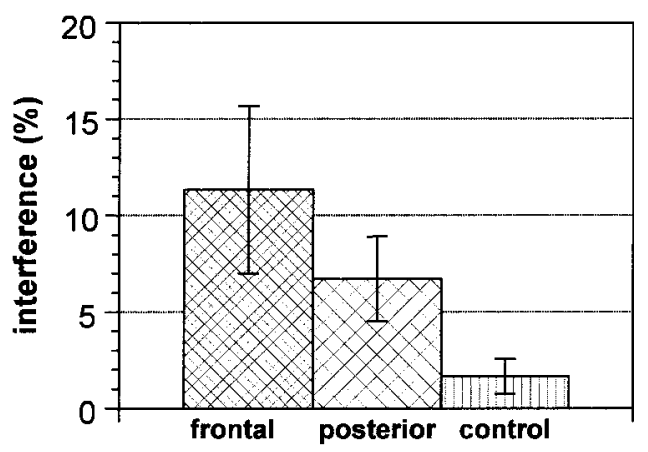

Figure 4. Mean group differences in the manual Stroop task. Interference scores indicate the percentage of error difference between the incongruent and the congruent conditions. Vertical bars represent standard errors of the mean. of goal-directed arm movements is followed by selective electromyographic activation if the primary motor cortex is concurrently stimulated by transcranial magnetic stimulation. Chartrand and Bargh (1999) were able to show that people tend to imitate the actions of their interaction partners in social situations. Furthermore, behavioral studies

Table 3

Correlation of Imitation-Inhibition Task and Stroop Task With Other Frontal Lobe Tests

\begin{tabular}{lcc}
\hline \multicolumn{1}{c}{ Test } & Imitation-inhibition & Stroop \\
\hline MCST & & \\
Perseverations & -.33 & $.73^{* *}$ \\
Conceptual losses & -.36 & $.64^{*}$ \\
Total errors & -.37 & $.59^{* *}$ \\
Categories & .45 & $-.58^{*}$ \\
Verbal Fluency & .30 & -.45 \\
DOT & -.04 & -.18 \\
\hline
\end{tabular}

Note. $\quad$ MCST $=$ Modified Wisconsin Card Sorting Test; DOT $=$ Digit Ordering Test.

$* p<.05$, two-tailed. $* * p<.01$, two-tailed. 
Table 4

Group Comparison of Other Frontal Lobe Tests

\begin{tabular}{|c|c|c|c|c|c|c|}
\hline \multirow[b]{2}{*}{ Test } & \multicolumn{2}{|c|}{ Frontal lesion } & \multicolumn{2}{|c|}{$\begin{array}{c}\text { Nonfrontal } \\
\text { lesion }\end{array}$} & \multicolumn{2}{|c|}{ Control } \\
\hline & $M$ & $S D$ & $M$ & $S D$ & $M$ & $S D$ \\
\hline \multicolumn{7}{|l|}{ MCST } \\
\hline Perseverations & 1.9 & 3.8 & 1.1 & 1.3 & 0.5 & 1.3 \\
\hline Conceptual losses & 0.3 & 0.6 & 0.4 & 0.7 & 0.0 & 0.2 \\
\hline Total errors & 6.9 & 3.8 & 7.3 & 4.2 & 5.1 & 3.6 \\
\hline Categories & 6.2 & 1.5 & 6.1 & 1.1 & 6.7 & 0.9 \\
\hline Verbal Fluency & 30.9 & 9.8 & 27.7 & 8.0 & 38.4 & 7.9 \\
\hline DOT & 8.2 & 2.4 & 7.2 & 2.7 & 8.8 & 1.7 \\
\hline
\end{tabular}

Note. $\quad$ MCST $=$ Modified Wisconsin Card Sorting Test; DOT $=$ Digit Ordering Test.

have demonstrated that the observation of an incongruent action leads to interference, which has to be inhibited (Brass, Bekkering, \& Prinz, 2001; Brass et al., 2000; Stürmer, Aschersleben, \& Prinz, 2000). In a functional MRI study, we were able to show that such inhibitory mechanisms are related to the prefrontal cortex (Brass, Zysset, \& von Cramon, 2001). If participants were required to execute a predefined response while observing an incongruent action, inhibition-related activation was found in the prefrontal and parietal cortex. The present findings complete this picture by demonstrating that patients with frontal lesions fail to inhibit imitative response tendencies.

\section{The Inhibition of Imitative Response Tendencies: A Neuropsychological Perspective}

The assumption that the frontal cortex is involved in response inhibition is old (e.g., Luria, 1966). Only a few studies, however, have investigated the inhibition of imitative response tendencies. These investigations were primarily related to imitation behavior, which describes overt imitative responses (Lhermitte et al., 1986). In contrast to the proposal of Lhermitte and colleagues, who argued that imitation behavior is very frequent in patients with frontal lesions, the syndrome turned out to be not as frequent as suggested (De Renzi et al., 1996). Especially in patients with a relatively mild frontal syndrome, imitation behavior is not very likely to be observed. Consequently, it would be desirable to have a more sensitive measure of imitative response tendencies. The present study demonstrates that our methodology allows the investigation of relatively weak imitative response tendencies by using an interference paradigm.

The question arises whether a continuum exists from such covert imitative response tendencies to overt imitation behavior. Lhermitte and colleagues argued against a continuum such as this, stating that imitation behavior is an integral part of the conscious awareness of the patient and not an automatic or reflexive response (Lhermitte et al., 1986). However, on the basis of the theoretical background described above, another interpretation seems to be more likely: Echopractic responses and imitation behavior both are manifestations of the same deficit in inhibiting prepotent imitative response tendencies. Whereas patients with mild imitation-inhibition deficits might experience the echopractic response as unintended, the imitative response becomes a part of motor intentions in patients displaying imitation behavior. From this perspective, imitation behavior is a kind of anosognostic form of the failure to inhibit imitative response tendencies.

\section{Does a General Motor Inhibition Deficit Exist?}

Another central aim of the present study was to investigate whether the same inhibitory processes are involved in the inhibition of imitative responses and overlearned responses. Even if it is problematic to directly compare the imitation-inhibition task and the Stroop task because they differ in many aspects (e.g., the number of response alternatives), the present findings suggest a dissociation of both inhibitory mechanisms. First, performance in the Stroop task and performance in the imitation-inhibition task were completely uncorrelated. Second, the correlational pattern of both tasks with other frontal tasks was different. Third, some patients who showed an impaired performance in the Stroop task were not impaired in the imitation-inhibition task and vice versa.

Beside this general finding, the present data add some more information to the understanding of the neuronal mechanisms underlying the inhibition of automatic response tendencies. A controversy about the location of Stroop interference can be followed throughout the clinical literature on the Stroop task. The most convincing study was carried out by Vendrell and colleagues (1995), who argued that lesions to the right fronto-lateral cortices cause deficient Stroop performance. In contrast, our data suggest that lesions to both hemispheres cause deficits in the Stroop task. Regarding lesion sites that impaired performance in the imitation-inhibition task, lesions of the fronto-lateral cortex were more likely to produce deficits than any other frontal lesion. These results go together with recent brain imaging studies that show fronto-lateral activation in response inhibition tasks as assessed by the go/no-go paradigm (Garavan et al., 1999; Konishi et al., 1999). They also support the assumption of De Renzi and colleagues (1996) that lesions to the upper medial and lateral frontal cortex are responsible for imitation behavior (De Renzi et al., 1996). In spite of this, in our patient group with frontal lesions there was also 1 patient with orbitofrontal lesions who had a strongly impaired performance in the imitation-inhibition task. This finding is in accordance with the results of a functional MRI 
study we carried out only recently (Brass, Zysset, \& von Cramon, 2001). In this study, we found lateral and medial prefrontal areas to be involved in the inhibition of imitative response tendencies. We assume that these two brain areas have different functional roles in the inhibition of imitative responses. However, further research is needed to validate this assumption.

\section{Conclusion}

The present data show that patients with a relatively mild frontal syndrome have highly specific deficits to inhibit imitative response tendencies. Furthermore, it was demonstrated that the inhibition of imitative response tendencies and the inhibition of overlearned response tendencies are cortically unrelated. These findings suggest that the investigation of imitative response tendencies adds an important but neglected aspect to the understanding of frontal lobe functioning.

\section{References}

Anderson, S. W., Damasio, H., Jones, R. D., \& Tranel, D. (1991). Wisconsin Card Sorting Test performance as a measure of frontal lobe damage. Journal of Clinical and Experimental Neuropsychology, 13, 909-922.

Beringer, J. (1995). Experimental Run Time System [computer software]. Frankfurt, Germany: BeriSoft Cooperation.

Brass, M., Bekkering, H., \& Prinz, W. (2001). Movement observation affects movement execution in a simple response task. Acta Psychologica, 106, 3-22.

Brass, M., Bekkering, H., Wohlschläger, A., \& Prinz, W. (2000). Compatibility between observed and executed finger movements: Comparing symbolic, spatial, and imitative cues. Brain and Cognition, 44, 124-143.

Brass, M., Zysset, S., \& von Cramon, D. Y. (2001). The inhibition of imitative response tendencies. Neuroimage, 14, 1416-1423.

Chartrand, T. L., \& Bargh, J. A. (1999). The chameleon effect: The perception-behavior link and social interaction. Journal of Personality and Social Psychology, 76, 893-910.

Decety, J., Grezes, J., Costes, N., Perani, D., Jeannerod, M., Procyk, E., et al. (1997). Brain activity during observation of actions: Influence of action content and subject's strategy. Brain, 120, 1763-1777.

De Renzi, E., Cavalleri, F., \& Facchini, S. (1996). Imitation and utilisation behaviour. Journal of Neurology, Neurosurgery \& Psychiatry, 61, 396-400.

Di Pellegrino, G., Fadiga, L., Fogassi, L., Gallese, V., \& Rizzolatti, G. (1992). Understanding motor events: A neuropsychological study. Experimental Brain Research, 91, 176-180.

Fadiga, L., Fogassi, L., Pavesi, G., \& Rizzolatti, G. (1995). Motor facilitation during action observation: A magnetic stimulation study. Journal of Neurophysiology, 73, 2608-2611.

Gallese, V., Fadiga, L., Fogassi, L., \& Rizzolatti, G. (1996). Action recognition in the premotor cortex. Brain, 119, 593-609.

Garavan, H., Ross, T. J., \& Stein, E. A. (1999). Right hemispheric dominance of inhibitory control: An event-related functional MRI study. Proceedings of the National Academy of Sciences, USA, 96, 8301-8306.

Grafman, J., Jonas, B., \& Salazar, A. (1990). Wisconsin Card Sorting Test performance based on location and size of neuroanatomical lesion in Vietnam veterans with penetrating head injury. Perceptual and Motor Skills, 71, 1120-1122.
Grant, D. A., \& Berg, E. A. (1948). A behavioral analysis of degree of reinforcement and ease of shifting to new responses in a Weigl-type card-sorting problem. Journal of Experimental Psychology, 38, 404-411.

Grezes, J., Costes, N., \& Decety, J. (1999). The effects of learning and intention on the neural network involved in the perception of meaningless actions. Brain, 122, 1875-1887.

Hoppe, C., Müller, U., Werheid, K., Thöne, A., \& von Cramon, D. Y. (2000). Digit Ordering Test: Clinical, psychometric, and experimental evaluation of a verbal working memory test. The Clinical Neuropsychologist, 14, 38-55.

Horn, W. (1983). Leistungprüfsystem (LPS) [Performance Assessment System]. Göttingen, Germany: Verlag für Psychologie.

Iacoboni, M., Woods, R. P., Brass, M., Bekkering, H., Mazziotta, J. C., \& Rizzolatti, G. (1999, December 24). Cortical mechanisms of human imitation. Science, 286, 2526-2528.

Konishi, S., Nakajima, K., Uchida, I., Kikyo, H., Kameyama, M., \& Miyashita, Y. (1999). Common inhibitory mechanism in human inferior prefrontal cortex revealed by event-related functional MRI. Brain, 122, 981-991.

Lehrl, S. (1999). Mehrfach-Wortschatz-Intelligenztest (MWT-B) [Multiple Word-Choice Test]. Erlangen, Germany: Straube.

Lhermitte, F., Pillon, B., \& Serdaru, M. D. (1986). Human autonomy and the frontal lobes: I. Imitation and utilization behavior. A neuropsychological study of 75 patients. Annals of Neurology, 19, 326-334.

Luria, A. R. (1966). Higher cortical functions in man. New York: Basic Books.

Mountain, M. A., \& Snow, W. G. (1993). Wisconsin Card Sorting Test as a measure of frontal pathology: A review. The Clinical Neuropsychologist, 7, 108-118.

Nishitani, N., \& Hari, R. (2000). Temporal dynamics of cortical representation for action. Proceedings of the National Academy of Sciences, USA, 97, 913-918.

Nelson, H. E. (1976). A modified card-sorting test sensitive to frontal lobe defects. Cortex, 12, 313-324.

Nelson, H. E., \& Willison, J. (1991). National Adult Reading Test manual (2nd ed.). Windsor, England: NFER-Nelson.

Rizzolatti, G., Fogassi, L., \& Gallese, V. (2001). Neurophysiological mechanisms underlying the understanding and imitation of action. Nature Reviews Neuroscience, 2, 661-670.

Simon, J. R., \& Rudell, A. P. (1967). Auditory S-R compatibility: The effect of an irrelevant cue on information processing. Journal of Applied Psychology, 51, 300-304.

Stroop, J. R. (1935). Studies of interference in serial verbal reactions. Journal of Experimental Psychology, 18, 643-662.

Stürmer, B., Aschersleben, G., \& Prinz, W. (2000). Effects of correspondence between complex stimulus and response patterns. Journal of Experimental Psychology: Human Perception and Performance, 26, 1746-1759.

Vendrell, P., Junque, C., Pujol, J., Jurado, M. A., Molet, J., \& Grafman, J. (1995). The role of prefrontal regions in the Stroop task. Neuropsychologia, 33, 341-352.

Werheid, K., Hoppe, C., Thoene, A., Müller, U., Müngersdorf, M., $\&$ von Cramon, D. Y. (2002). The adaptive digit ordering test: Clinical application, reliability, and validity of a verbal working memory test. Archives of Clinical Neuropsychology, 17, 547565.

Received March 7, 2002

Revision received July 1, 2002

Accepted September 16, 2002 